\title{
Prenatal Playful-Educational Activities, Psycho-Emotional Well-Being of Pregnant Women and Perinatal Outcomes: A Pilot Study
}

\author{
Jaime Salvador-Moysén ${ }^{1 *}$, Blanca Edith Cobián-López², Yolanda Martínez-López ${ }^{1}$, \\ Edgar Felipe Lares-Bayona1, María del Socorro Páez-Güereca²
}

${ }^{1}$ Academic Group of Public Health and Epidemiology, Institute of Scientific Research, Universidad Juárez del Estado de Durango, Durango, México

${ }^{2}$ Child Care and Development Center "Francisco Villa", Durango, México

Email: ^jsmoysen@gmail.com

How to cite this paper: Salvador-Moysén, J., Cobián-López, B.E., Martínez-López, Y., Lares-Bayona, E.F. and del Socorro PáezGüereca, M. (2021) Prenatal Playful- Educational Activities, Psycho-Emotional WellBeing of Pregnant Women and Perinatal Outcomes: A Pilot Study. Open Journal of Obstetrics and Gynecology, 11, 102-116. https://doi.org/10.4236/ojog.2021.112012

Received: January 14, 2021

Accepted: February 22, 2021

Published: February 25, 2021

Copyright $\odot 2021$ by author(s) and Scientific Research Publishing Inc. This work is licensed under the Creative Commons Attribution International License (CC BY 4.0).

http://creativecommons.org/licenses/by/4.0/

(c) (i) Open Access

\begin{abstract}
Objective: To present the results of a pilot study that evaluated the psycho-emotional well-being, and the perinatal results of a group of 44 women who attended a prenatal program that incorporates playful and educational activities, in a Child Development Center in Durango. Mexico. Methods: A group of 44 women with informed consent participated for 28 weeks in the prenatal program. The condition of psycho-emotional well-being during the first and third trimesters and the perinatal results were analyzed with validated instruments. Physiological stress was also assessed with salivary cortisol in the same trimesters. Results: More than $90 \%$ of the women evaluated their psycho-emotional condition as satisfactory and very satisfactory. The evaluation of anxiety in its Trait/State modalities placed the participants in the category of mild and moderate. Salivary cortisol showed values within a normal range. Perinatal results showed that $98 \%$ of deliveries were at term, $93 \%$ of newborns weighed more than 2500 grams, and $98 \%$ of newborns had an APGAR score of 9 at 5 minutes. Conclusion: The results suggest that the incorporation of playful and educational actions to prenatal surveillance positively influenced the biopsychosocial condition of the pregnant woman and favorable perinatal outcomes.
\end{abstract}

\section{Keywords}

Prenatal Care, Prenatal Education, Playful Activities, Maternal Health, Healthy Pregnancy, Comprehensive Health Care 


\section{Introduction}

The actions of a medical nature have been privileged as the central axis of prenatal control and without a doubt have had a favorable impact in the conditions of the gestational outcome [1]. It is important to highlight, however, a series of non-medical actions that positively influence the development of pregnancy has been recognized and documented.

The interventions reported in numerous studies are of a different nature (psychoeducational, sport, musical and playful) [2]-[10]. The favorable results obtained with these interventions can be explained by the findings obtained in different studies by Peter Sterling [11] and Bruce McEwen [12] referring to allostasis (Physiological stability achieved by regulatory systems, adjusting to different demands through change) and allostatic load (Wear caused by chronic hyperactivity or hypoactivity of the different systems that protect the body from internal or external stress); processes that allude to the individual's adaptive or failed responses to different conditions of the psychosocial environment.

Sterling and McEwen's approaches, findings and conclusions make possible to understand how playful, sport and musical activities carried out during pregnancy help maintaining a balanced response of the hypothalamic-pituitary-adrenal axis, and of the cardiovascular, metabolic and immune systems. All this favors the allostatic balance and psychophysiological resistance in situations of increased biological demand or adversity. These aspects have been widely developed among others, by authors such as John C. Wingfield [13].

John Cassel demonstrated, more than 40 years ago, the beneficial effect of favorable conditions of an environment of psychosocial support for pregnant women. Cassel made designs that allowed comparing groups of women who lived in two different psychosocial contexts: a group whose context was evaluated with favorable scores and another group whose context was characterized by the presence of psychosocial stressors and little psychosocial support. The difference in gestational evolution and perinatal outcomes clearly favored women who were located in a more satisfactory psychosocial context, as this group presented a lower rate of complications compared to women located in an adverse context [14] [15].

However, it is from the theoretical and empirical contributions of Sterling and McEwen that the concepts of allostasis and allostatic load are established and a satisfactory explanatory framework is constructed that allow us to understand the adaptive or failed biological response to various psychosocial scenarios.

\section{The Objectives of the present study were:}

- To assess the psycho-emotional well-being of pregnant women who participated in the playful-educational activities.

- Evaluate the perinatal outcomes of the participating women.

\section{Material and Methods}

Study Design and Participants. 
A pilot intervention study [16] was designed in which 44 pregnant women enrolled in a Prenatal Surveillance Program agreed to participate. There were no exclusion criteria. The participants regularly attended the Program developed at a Child Development Center in the city of Durango; Mexico during the period between October 2013 and April 2015. During the gestational process, the group of women regularly participated in different playful and educational activities that are part of the Prenatal Surveillance Program. In week 12 and week 37 of pregnancy, we assessed the conditions of Subjective Wellbeing, the perception of Anxiety in its Trait/State modalities. Salivary samples were also taken at 8:00 am and 20:00 pm for cortisol measurement, an indicator of physiological stress and allostatic balance. The first evaluation is considered the baseline measurement, whilst the second in week 37 is considered the final one and represents the moment in which the impact of the educational playful actions is evaluated (Figure 1).

Sample size estimation [17].

The following formula (17) was used to estimate the sample size:

$$
\mathrm{n}=\mathrm{N} * \mathrm{Z}^{2} \alpha / 2 * \mathrm{p} *(1-\mathrm{p}) / \mathrm{d}^{2}(\mathrm{~N}-1)+\mathrm{Z}^{2} \alpha / 2 * \mathrm{p} *(1-\mathrm{p})
$$

where,

$\mathrm{n}=$ Sample size.

$\mathrm{N}=$ Population size $=44$ pregnancies in the CADI.

$\mathrm{Z}=$ Confidence level $(95 \%)=$ critical value 1.96 (two tails).

$\mathrm{p}=$ approximate proportion of the study phenomenon in the reference population $=10 \%$ of newborns with low birth weight in Latin America and the Caribbean (<2500 grs.) (UNICEF.ORG).

$\mathrm{q}=$ proportion of the reference population that does not present the study phenomenon $=1-\mathrm{p}=90 \%$.

$\mathrm{d}=$ study accuracy $=5 \%=0.05$.

$\mathrm{n}=34$.

\subsection{Description of the Playful Activities of the Prenatal Program}

The playful and educational activities are taught for 28 weeks: from gestational week 12 until week 40 or at the end of pregnancy. The activities carried out are the following: medical surveillance, prenatal yoga, psycho-emotional stimulation, music therapy.

For 3 days a week, the assistance is 3 hours a day. The prenatal program is carried out in a warm and friendly environment, a series of playful and sensory activities are carried out, allowing the recognition of the importance of pregnancy, living it in a conscious way which allows to acquire tools necessary to live the pregnancy in a harmonious and healthy way as well as providing the newborn with comprehensive care.

Table 1 shows the Prenatal Medical Surveillance and Prenatal Control.

Each member of the program has a prenatal control card, and there is a monthly clinical follow-up based on the Official Mexican Standard NOM-007-SSA-2016. Talks are given once a week with a duration of 1 hour and a half each, with var- 
ious topics related to the gestational process; evolution of pregnancy, lactation and care of the newborn. The subjects are taught by specialists from the following fields: pediatrics, gyneco-obstetrics, genetics, physical therapy and neurodevelopment.

Yoga-prenatal. It is taught by qualified instructors. There are 2 classes per week from admission to the end of pregnancy, it is divided into 2 groups; participants who are less than 20 weeks pregnant and participants who are more than 20 weeks pregnant, classes are held in two-hour sessions.



Figure 1. General Scheme of the Study. Pilot intervention study to evaluate the impact of a playful-educational intervention on psycho-emotional well-being and on the perinatal results of a group of users who regularly attended a Prenatal Surveillance Program. 
Table 1. Prenatal medical surveillance and prenatal control.

\begin{tabular}{|c|c|}
\hline $\begin{array}{l}\text { Prenatal Medical Surveillance } \\
\text { Child Development Center }\end{array}$ & $\begin{array}{l}\text { Prenatal Control } \\
\text { Ministry of Health }\end{array}$ \\
\hline
\end{tabular}

The pregnant woman enters the prenatal program in the 12 th week of her gestational process, is attended by the doctor responsible for the program, a medical history (CLAP/SMR)* PAHO $^{* *}$ is performed. Which is composed of: clinical record, family history and personal, obstetric antecedents, current pregnancy. The following data are recorded on the first visit: weight, blood pressure, uterine height, presentation, fetal heart rate, fetal movements, iron intake, Calcium, folates, nutritional status is assessed and warning signs of pregnancy are reported. Subsequently, 7 visits are scheduled one each month and the same data recorded above are recorded. After birth the mother is cited to complete the filling of the (CLAP/SMR) PAHO with the birth and newborn data
Each of the women participating in the prenatal program receives the attention of a doctor from the Ministry of Health who is responsible for prenatal control and month after month performs the clinical review and evaluates the conditions of pregnancy, records the data in your card Prenatal, which the patient will show to the doctor responsible for the prenatal program who performs the prenatal medical surveillance and monitors compliance with the medical indications for each particular case.

${ }^{\star}$ Latin American Center for Perinatology, Women’s Health and Reproductive; ${ }^{*}$ Pan American Health Organization.

Psycho-emotional stimulus.

In this area a psychotherapist works at two levels: general and personal.

1) General level

Weekly talks are given at the general level, on Thursdays from 6:30 a.m. to 8:00 p.m. addressed to the parents of future babies. The thematic proposal seeks to review aspects of interest that give these parents a greater chance of being better with themselves, as individuals and as a couple, as well as the points that most often hinder family relationships and children's emotional growth. With greater welfare of parents, greater welfare of the little ones.

2) Personal level

In some cases when reviewing the different issues, personal emotional situations arise, awareness of unresolved conflicts, absences or feelings of emptiness is made.In these cases, upon request, a personal process is followed with the consulting psychologist.

Music therapy.

A musical session of 1:30 hrs. per week was taken, where music provided concentration, relaxation and active stimulation. The musical sessions were enriched with activities where diverse themes, advice, orientations, and reflections were raised in order to help the good course of the gestational process.

\subsection{Ethical Considerations}

Participants were verbally informed in detail about the study, as well as the confidential and anonymous nature of the information obtained. The study was approved by the Research Ethics Committee of the Scientific Research Institute of the Juárez University of the State of Durango. The total number of women who were invited agreed to participate and signed an informed consent letter.

Study Instruments.

- Sociodemographic Data Questionnaire. 
In order to know the sociodemographic situation, a socioeconomic and demographic study format was used to obtain the data about school level, occupation and economic income of the participant and her spouse or partner.

- Perinatal Clinical History-CLAP-PAHO-WHO [18].

For the evaluation of the prenatal control, the card (CLAP-PAHO-WHO) was used, which begins the data recording upon admission, continues during the pregnancy and, subsequently, an appointment is made to record the birth conditions. Prenatal control was carried out with a monthly review of the card, which collects the most important clinical data of the pregnant woman related to the evolution of the pregnancy.

With the purpose of knowing the conditions of subjective well-being and psycho-emotional balance of the participating women, the following instruments were applied.

Inventory of Subjective Wellbeing of Alicia Omar et al. [19] [20].

Of this Inventory, the questions corresponding to the following dimensions were applied: Achievements, self-confidence to face difficulties, transcendence, support of the family group and social support. A Likert scale was used to record and evaluate the answers corresponding to the 18 questions of the five dimensions analyzed.

Three categories were formed according to the score obtained by the participants.

31 points or less. Unsatisfactory.

32 to 44 points. Satisfactory.

45 points or more. Very satisfactory.

Inventory of Anxiety in its modalities Trait/State of Díaz-Guerrero and Spielberger [21] [22].

Was used to evaluate Anxiety of the participants in their Trait/State modalities.

Four categories were formed for evaluation of Anxiety in its Trait/State modalities [23].

20 to 31 points. Minimum.

32 to 43 points. Mild.

44 to 55 points. Moderate.

56 points or more. High.

With the purpose of having a biological indicator that measured the conditions of psycho-emotional stability of pregnant women. Salivary cortisol was measured at the beginning and at the end of the playful-educational intervention.

\section{Salivary Cortisol Measurement.}

For the measurement of salivary cortisol, two saliva samples were collected at 8:00 am and at 8:00 pm at two moments of the gestational process, week 12 during the first trimester and week 37 during the third trimester. Samples were stored in the Molecular Biology laboratory of the Scientific Research Institute of the Juárez University of the State of Durango. The samples were centrifuged at 
$1000 \mathrm{~g}$ for $5 \mathrm{~min}$, decanted to preserve saliva without mucus, and frozen at $-20^{\circ} \mathrm{C}$ until analysis. The concentration of salivary cortisol was determined by immunoassay in microplates. (Active ${ }^{\oplus}$ Cortisol EIA, Diagnostic Systems Laboratories, Inc. Webster, TX). with an ELx800 (Lionheart Diagnostics, Marshall MI.) Universal plate reader at $450 \mathrm{~nm} 14$ [24].

Clinical and Anthropometric Assessment.

Calibrated instruments were used for clinical and somatometric assessment: Anthropometer, Sphygmomanometer and Stethoscope.

Statistic analysis.

For the statistical analysis of the data, measures of central tendency and dispersion were used, as well as percentage values for a descriptive statistic; the parametric inference methods were with $\mathrm{t}$-student. We used the paired student's $t$ to compare salivary cortisol averages at different times, with different sample sizes [25].

\section{Results}

\section{Sociodemographic}

$27(61 \%)$ of the participating women were in the range of 21 to 30 years of age, $11(25 \%)$ were located in the range of 31 to 35 years, 4 (9\%) in the range of 16 to 20 years and $2(5 \%)$ in the age group of 35 to 40 years. With reference to their civil status, 26 (59\%) women reported being married, 11 (25\%) participants said they were single and 7 (16\%) said they were in free union. The level of schooling referred by the participants showed that 24 (55\%) women reported having university and postgraduate studies, 15 (34\%) pre-university studies and 5 (11\%) high school studies. The occupation manifested by the participating mothers was distributed as follows: 20 (45\%) reported professional activities, 10 (23\%) employed, 9 (21\%) students, and 5 (11\%) said they were housewives.

\section{Somatometric, clinical and obstetric data}

The average body mass index (BMI) observed in the initial evaluation was 25.8 with $\sigma$ of 4.8. The average value in the first trimester of Mean blood pressure was $81.2 \mathrm{mmHg}$ with $\sigma$ of 4.2 and the average value in the third trimester was $85.1 \mathrm{mmHg}$ with $\sigma$ of 7.5 The total number of participating women received supplements with iron, folic acid and calcium since the beginning of their prenatal control. The obstetric data recorded were the following: 15 (34\%) participants were in their first pregnancy, 20 (45\%) the second, 7 (16\%) the third, and 2 (5\%) women the fourth pregnancy.

Table 2 shows the Subjective well-being.

Between $92 \%$ and $100 \%$ of the participating women, according to their age group, obtained a score during the first quarter that corresponds to satisfactory and very satisfactory in the 5 dimensions evaluated. Between $83 \%$ and $100 \%$ of the women of the study group were located during the third quarter, according to their age group, in a satisfactory and very satisfactory condition in the $5 \mathrm{di}$ mensions evaluated. 
Table 2. Subjective Well-being Categories.

\begin{tabular}{|c|c|c|c|c|}
\hline \multirow{2}{*}{$\begin{array}{c}\text { Categories by age groups } \\
\text { Under } 25 \text { years }\end{array}$} & \multicolumn{2}{|c|}{$\begin{array}{c}\text { First Trimester } \\
\text { (12 weeks of gestation) }\end{array}$} & \multicolumn{2}{|c|}{$\begin{array}{c}\text { Third Trimester } \\
\text { (37 - } 40 \text { weeks of gestation) }\end{array}$} \\
\hline & $\mathrm{n}$ & $\%$ & $\mathrm{n}$ & $\%$ \\
\hline Very satisfactory & 4 & 31 & 4 & 33 \\
\hline Satisfactory & 8 & 62 & 6 & 50 \\
\hline Unsatisfactory & 1 & 7 & 2 & 17 \\
\hline Summation & 13 & 100 & 12 & 100 \\
\hline 25 to 34 years & $\mathrm{n}$ & $\%$ & $\mathrm{n}$ & $\%$ \\
\hline Very satisfactory & 13 & 50 & 8 & 38 \\
\hline Satisfactory & 11 & 42 & 12 & 57 \\
\hline Unsatisfactory & 2 & 8 & 1 & 5 \\
\hline Summation & 26 & 100 & 21 & 100 \\
\hline$\geq 35$ years & $\mathrm{n}$ & $\%$ & $\mathrm{n}$ & $\%$ \\
\hline Very Satisfactory & 3 & 60 & 3 & 60 \\
\hline Satisfactory & 2 & 40 & 2 & 40 \\
\hline \multicolumn{5}{|l|}{ Unsatisfactory } \\
\hline Summation & 5 & 100 & 5 & 5 \\
\hline Total & 44 & 100 & 38 & 100 \\
\hline
\end{tabular}

Source. Questionnaires applied; ${ }^{\star}$ Due to medical circumstances and home change, the questionnaire was not applied in the third trimester in 6 women.

Table 3 and Table 4 show the different levels of state/trait anxiety presented by the participating women according to the age group. The average values observed in the studied group were located mainly in both quarters and in both modalities, in the categories of mild and moderate anxiety.

Figure 1 shows the salivary cortisol. The average values of salivary cortisol $(\mu \mathrm{g} / \mathrm{dL})$ during the two gestational moments are within a normal range [26]. When comparing the results obtained during the first gestational trimester versus the third, statistically significant differences were observed in the measurements at 8:00 am and 8:00 pm, with cortisol values being lower in the third trimester (Figure 2).

Perinatal Results.

40 (98\%) of the participants had a term pregnancy and 1 (2\%) case was preterm pregnancy. In the group of term newborns, 38 (95\%) showed normal weight and 2 (5\%) expressed low weight ( $<2500$ grams). The only preterm newborn also expressed low weight. It was registered as a total percentage of low birth weight in the total group of newborns, $7 \%$ (3 cases), 2 cases in term preg- 
nancies, and one case in the preterm pregnancy. 40 (98\%) newborns obtained an APGAR score of 9 at 5 minutes and one newborn (2\%) expressed a score of 8 . (Due to medical circumstances and home change, it was not possible to obtain the pregnancy resolution information in 3 of the participants).

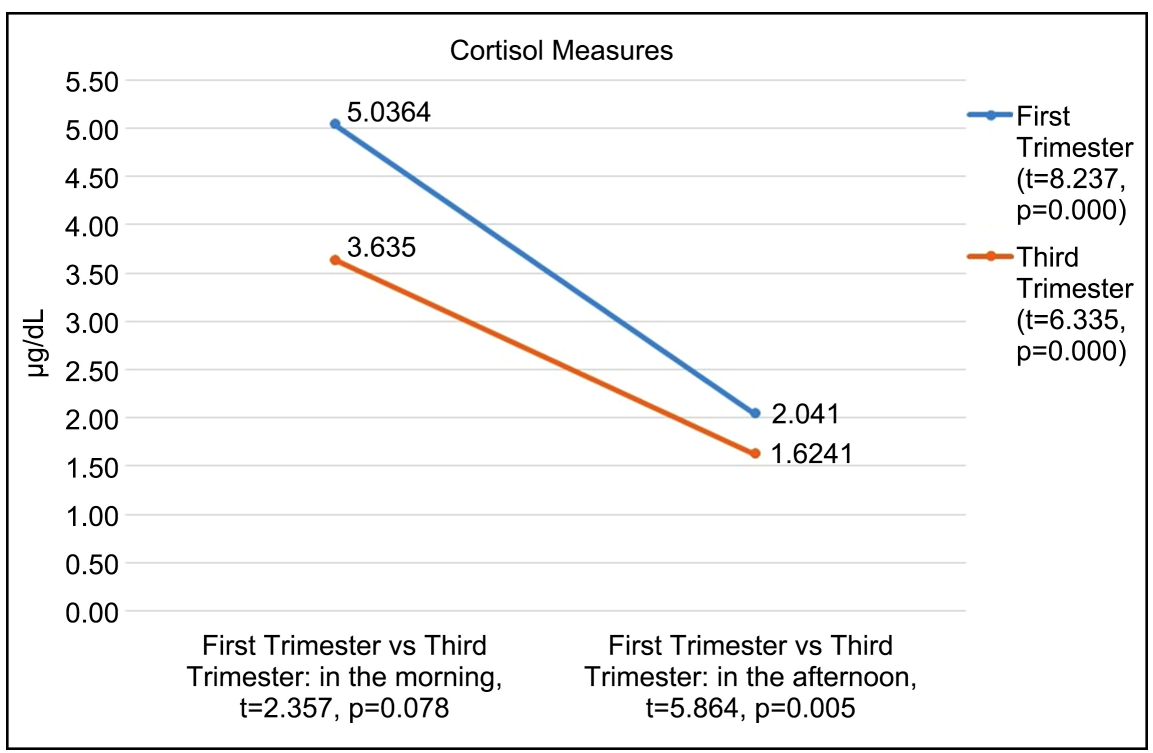

Figure 2. Salivary cortisol results during the first and third trimesters.

Table 3. Levels of anxiety in its state modality by age groups.

\begin{tabular}{|c|c|c|c|c|}
\hline \multirow{2}{*}{$\begin{array}{c}\text { Levels by age groups } \\
\text { Under } 25 \text { years }\end{array}$} & \multicolumn{2}{|c|}{$\begin{array}{c}\text { First Trimester } \\
\text { (12 weeks of gestation) }\end{array}$} & \multicolumn{2}{|c|}{$\begin{array}{c}\text { Third Trimester } \\
\text { (37 - } \mathbf{4 0} \text { weeks of gestation }\end{array}$} \\
\hline & $\mathrm{n}$ & $\%$ & $\mathrm{n}$ & $\%$ \\
\hline Mild & 3 & 23 & 6 & 50 \\
\hline Moderate & 10 & 77 & 6 & 50 \\
\hline Summation & 13 & 100 & 12 & 100 \\
\hline 25 to 34 years & $\mathrm{n}$ & $\%$ & $\mathrm{n}$ & $\%$ \\
\hline Mild & 14 & 54 & 9 & 41 \\
\hline Moderate & 12 & 46 & 13 & 59 \\
\hline Summation & 26 & 100 & 22 & 100 \\
\hline$\geq 35$ years & $\mathrm{n}$ & $\%$ & $\mathrm{n}$ & $\%$ \\
\hline Mild & 4 & 80 & 2 & 40 \\
\hline Moderate & 1 & 20 & 3 & 60 \\
\hline Summation & 5 & 100 & 5 & 100 \\
\hline Total & 44 & 100 & 39 & 100 \\
\hline
\end{tabular}

Source. Questionnaires applied. The questionnaire was not applied in the third trimester in 5 women due to different circumstances. 
Table 4. Levels of anxiety in its trait modality by age groups.

\begin{tabular}{|c|c|c|c|c|}
\hline \multirow{2}{*}{$\begin{array}{c}\text { Levels by age groups } \\
\text { Under } 25 \text { years }\end{array}$} & \multicolumn{2}{|c|}{$\begin{array}{c}\text { First Trimester } \\
\text { (12 weeks of gestation) }\end{array}$} & \multicolumn{2}{|c|}{$\begin{array}{c}\text { Third Trimester } \\
(37-40 \text { weeks of gestation) }\end{array}$} \\
\hline & $\mathrm{n}$ & $\%$ & $\mathrm{n}$ & $\%$ \\
\hline Mild & 8 & 62 & 7 & 58 \\
\hline Moderate & 3 & 23 & 5 & 42 \\
\hline High & 2 & 15 & & \\
\hline Summation & 13 & 100 & 12 & 100 \\
\hline 25 to 34 years & $\mathrm{n}$ & $\%$ & $\mathrm{n}$ & $\%$ \\
\hline Mild & 9 & 35 & 9 & 41 \\
\hline Moderate & 16 & 61 & 13 & 59 \\
\hline High & 1 & 4 & & \\
\hline Summation & 26 & 100 & 22 & 100 \\
\hline$\geq 35$ years & $\mathrm{n}$ & $\%$ & $\mathrm{n}$ & $\%$ \\
\hline Mild & 4 & 80 & 2 & 40 \\
\hline Moderate & 1 & 20 & 3 & 60 \\
\hline Summation & 5 & 100 & 5 & 100 \\
\hline Total & 44 & 100 & 39 & 100 \\
\hline
\end{tabular}

Source. Questionnaires applied. The questionnaire was not applied in the third trimester in 5 women due to different circumstances.

\section{Discussion}

The results obtained from the Subjective Wellbeing Inventory, showed that more than $90 \%$ of the participating women were in the satisfactory and very satisfactory categories both in the first and in the third quarter, with the exception of the group of women under 25 years who showed a $83 \%$ score in the third quarter. These results show a positive balance between the cognitive and emotional aspects of the participants throughout the gestational process, as well as a favorable perception of family and social support [27].

The results obtained with the application of IDARE during the first quarter, to measure the levels of anxiety in the participants according to age group were mainly placed in the category of mild and moderate anxiety in the two modalities evaluated; It should be noted that 3 (6.8\%) women aged 34 years and younger showed high levels of anxiety in the trait modality. The average values in the third quarter measurement showed similar results to those of the first quarter; although there were no cases with high levels of anxiety in either of the two modalities.

The comparison with other studies carried out in our country shows the following: An investigation carried out by Arroyo-Guadarrama et al. [23] showed 
that in a group of pregnant women who formed a control group, $77 \%$ of the members were in the category of mild anxiety, $14 \%$ qualified as moderate anxiety and $9 \%$ were placed in the category of severe anxiety in the trait modality. In the modality of state the values observed were: mild anxiety $74 \%$, moderate anxiety $16 \%$ and severe anxiety $10 \%$. In another investigation conducted by Terrones et al. in a group of healthy pregnant adolescents, the average values were mild anxiety in both modalities [28]. It is important to underline that the average values observed in our work remained within the range of mild and moderate levels without significant increases.

With reference to the average values of salivary cortisol in the first trimester, figures were observed within a normal range and similar to those found by Lavalle-González et al. [26] in a population of young adults in northeastern Mexico. In our study, the figures obtained during the third quarter decreased when compared to the first quarter, and a statistically significant difference was observed when comparing the measurements made in both quarters. It is important to note that in contrast with the increase in cortisol levels at the end of the gestational process usually observed in pregnancy, in here we observe that the values obtained in the third trimester were lower than those observed in the first trimester, although remaining within a normal range. This finding can be interpreted as a result of the biological conditions of allostatic equilibrium achieved during the gestational process.

In our study the incidence of preterm pregnancies was $2 \%$ ( 1 case). Other works carried out in Mexico present the following information: An investigation developed by Minguet-Romero et al.; in a Social Security Institution at a national level it reported an incidence of $7.7 \%$ [29]. In another study conducted by López-García et al., a 7.7\% incidence of prematurity was observed in a high-specialty naval hospital [30]. Other research conducted by Pérez Molina et al in a teaching hospital in the state of Jalisco documented an incidence of prematurity of $3.4 \%$ [31].

Of the total of newborns of the women participating in our study, a low birth weight was observed in $3(7 \%)$ of them. The data reported by other authors in Mexico show the following figures: Franco-Monsreal et al. reported a frequency of $7.3 \%$ of low birth weight in a study conducted in Quintana Roo [32]. Another study realized by Rodríguez-Guzmán et al. reported a prevalence of $5.7 \%$ of low birth weight [33]. According to the World Health Organization, the prevalence of low weight at birth in Latin America and the Caribbean is 9\% [34].

With the previous data it can be affirmed that the perinatal results observed in the group of women we studied are satisfactory. The consistency observed between the different indicators evaluated in the participating women, both subjective and biological, allow us to clearly appreciate the biopsychosocial balance that the participants showed throughout their gestational process. It is important to underline the relevant contribution of the playful and educational activities to reach this achievement. 
The results obtained in this study show consistency with the numerous works carried out in order to show the benefits they have during the development of the gestational process; activities of a different nature, whether sports, educational or playful [2]-[10].

Although this study did not incorporate a control group, the evaluation carried out at two different gestational moments with standardized procedures, the regularity in the qualitative and biochemical measurements in the two quarters evaluated, with a range of normal values and without important differences between the two measurements, are indicators of methodological rigor that support the validity of the findings.

We consider that it is important to carry out studies of an analytical nature-with larger population samples-which will make it possible to elucidate more clearly the effect of playful and educational actions that are incorporated into prenatal surveillance programs. And on another plane it is also important that prenatal surveillance programs are established as a priority public health policy, aimed at improving the coverage and equating the quality of interventions aimed at achieving the best health conditions for pregnant women [35] [36].

\section{Conclusion}

The results strongly suggest, due to their plausibility and coherence, that the incorporation of playful and educational actions to prenatal surveillance, had a positive influence on the biopsychosocial condition of the pregnant woman and favorable perinatal results.

\section{Acknowledgements}

We wish to acknowledge to Dr. Lilia Vélez Vélez her collaboration in the measurement of salivary cortisol, in the samples obtained from the group of participants in the study.

\section{Authors' Contributions}

JS, BC, YM, EL, and MP contributed to the conceptualization, theoretical orientation and design of the study. BC organized the database. JS, EL, YM performed the statistical analysis. JS, wrote the first draft of the manuscript. All authors contributed to the revision of the manuscript, read it, discussed and approved the final version.

\section{Conflicts of Interest}

The authors declare no conflicts of interest in relation to the conduct of the research and the writing of the manuscript.

\section{References}

[1] Alexander, G.R. and Kotelchuck, M. (2001) Assessing the Role and Effectiveness of 
Prenatal Care: History, Challenges and Directions for Future Research. Public Health Reports, 116, 306-316. https://doi.org/10.1016/S0033-3549(04)50052-3

[2] Brantsaeter, A.L., Owe, K.M., Haugen, M., Alexander, J., Meltzer, H.M. and Longnecker, M.P. (2010) Validation of Self-Reported Recreational Exercise in Pregnant Women in the Norwegian Mother and Child Cohort Study. Scandinavian Journal of Medicine \& Science in Sports, 20, e48-e55. https://doi.org/10.1111/j.1600-0838.2009.00896.x

[3] Mudd, L.M., Owe, K.M., Mottola, M.F. and Pivarniki, J.M. (2013) Health Benefits of Physical Activity during Pregnancy: An International Perspective. Medicine \& Science in Sports \& Exercise, 45, 268-277. https://doi.org/10.1249/MSS.0b013e31826cebcb

[4] Magnus, P., Trogstad, L., Owe, K.M., Olsen, S.F. and Nystad, W. (2008) Recreational Physical Activity and the Risk of Preeclampsia: A Prospective Cohort of Norwegian Women Per Magnus. American Journal of Epidemiology, 168, 952-957. https://doi.org/10.1093/aje/kwn189

[5] Cramer, H., Frawley, J., Steel, A., Hall, H., Adams, J., Broom, A. and Sibbritt, D. (2015) Characteristics of Women Who Practice Yoga in Different Locations during Pregnancy. BMJ Open, 5, e008641. https://doi.org/10.1136/bmjopen-2015-008641

[6] Curtis, K., Weinrib, A. and Katz, J. (2012) Systematic Review of Yoga for Pregnant Women: Current Status and Future Directions. Evidence-Based Complementary and Alternative Medicine, 2012, Article ID: 715942. https://doi.org/10.1155/2012/715942

[7] Ferraro, Z.M., Chaput, J.P., Gruslin, A. and Adamo, K.B. (2014) The Potential Value of Sleep Hygiene for a Healthy Pregnancy: A Brief Review. ISRN Family Medicine, 2014, Article ID: 928293. https://doi.org/10.1155/2014/928293

[8] Lara, M.A., Navarro, C. and Navarrete, L. (2010) Outcome Results of a Psycho-Educational Intervention in Pregnancy to Prevent PPD: A Randomized Control Trial. Journal of Affective Disorders, 122, 109-117.

https://doi.org/10.1016/j.jad.2009.06.024

[9] Arya, R., Chansoria, M., Konanki, R. and Tiwari, D.K. (2012) Maternal Music Exposure during Pregnancy Influences Neonatal Behaviour: An Open-Label Randomized Controlled Trial. International Journal of Pediatrics, 2012, Article ID: 901812. https://doi.org/10.1155/2012/901812

[10] Martínez, V.R., Gutiérrez, P.J.A., Petersen, U.A., García, H.H.A., Ávalos-Huizar, L.M., Gutiérrez, G.H., Gutiérrez, C.D.A., González, C.L.F. and Valle-Delgado, E. (2015) Music Therapy in a Neonatal Intensive Care Unit: Beneficial Experience for the Binomial. Perinatología y Reproducción Humana, 29, 95-98.

https://doi.org/10.1016/j.rprh.2015.12.002

[11] Sterling, P. (2004) Principles of Allostasis: Optimal Design, Predictive Regulation, Pathophysiology and Rational Therapeutics. In: Schulkin, J., Ed., Allostasis, Homeostasis, and the Costs of Adaptation, Cambridge University Press, New York, 17-64. https://doi.org/10.1017/CBO9781316257081.004

[12] McEwen, B.S. (2008) Central Effects of Stress Hormones in Health and Disease: Understanding the Protective and Damaging Effects of Stress and Stress Mediators. European Journal of Pharmacology, 583, 174-185.

https://doi.org/10.1016/j.ejphar.2007.11.071

[13] Wingfield, J.C. (2004) Allostatic Load and Life Cycles: Implications for Neuroendocrine Control Mechanisms. In: Schulkin, J., Ed., Allostasis, Homeostasis, and the Costs of Adaptation, Cambridge University Press, New York, 302-342. 
https://doi.org/10.1017/CBO9781316257081.011

[14] Nuckolls, K.B., Kaplan, B.H. and Cassel, J. (1972) Psychosocial Assets, Life Crisis and the Prognosis of Pregnancy. American Journal of Epidemiology, 95, 431-441. https://doi.org/10.1093/oxfordjournals.aje.a121410

[15] Cassel, J. (1974) Psychosocial Processes and "Stress": Theoretical Formulation. International Journal of Health Services, 4, 471-482. https://doi.org/10.2190/WF7X-Y1L0-BFKH-9QU2

[16] Des Jarlais, D.C., Lyles, C., Crepaz, N. and the Trend Group (2004) Improving the Reporting Quality of Nonrandomized Evaluations of Behavioral and Public Health Interventions: The TREND Statement. AJPH, 94, 361-366. https://doi.org/10.2105/AJPH.94.3.361

[17] Pagano, M. and Kimberlee, G. (2000) Fundamentals of Biostatistics. 2nd Edition, Thomson Learning, Mexico.

[18] Fescina, R.H., De Mucio, B., Martínez, G., Díaz Rossello, J.L., Durán, P., Serruya, S., Mainero, L. and Rubino, M. (2011) Perinatal Information System (PIS): Perinatal Medical History: Filling Instructions and Definition of Terms. CLAP/SMR, Montevideo. CLAP/SMR. Publicación científica; 1584.

[19] Omar, A., Paris, L., de Souza, M.A., Almeida, S.H. and del Pino Peña, R. (2009) Validation of the Subjective Well-Being Inventory with Samples of Argentine, Brazilian and Mexican Youth and Adolescents. Suma Psicológica, 16, 69-84.

[20] Vera-Villarroel, P., Celis-Atenas, K., Pavez, P., Lillo, S., et al. (2012) Age and Happiness: Association of Subjective Wellbeing with Socio-Demographic Variables. Revista Latinoamericana de Psicología, 44, 155-163.

[21] Díaz-Guerrero, R. and Spielberger, C.D. (1975) IDARE: Trait-State Anxiety Inventory. El Manual Moderno, Mexico.

[22] González Llaneza, F. (2007) Instruments of Psychological Assessment. Editorial Ciencias Médicas, Havana Cuba.

[23] Arroyo-Guadarrama, S., Vite-Sierra, A. and Córdova-Barrios, A. (2014) Evaluation of Psychological Symptoms in Women with High-Risk Pregnancy. Atencion Farmaceutica, 21, 113-116. https://doi.org/10.1016/S1405-8871(16)30031-1

[24] De Weerth, C., Graat, G., Buitelaar, J.K. and Thijssen, J.H. (2003) Measurement of Cortisol in Small Quantities of Saliva. Clinical Chemistry, 49, 658-660. https://doi.org/10.1373/49.4.658

[25] Pedrosa, I., Juarros, J., Robles, A., Basteiro, J. and García, E. (2015) Goodness-of-Fit Tests in Skewed Distributions What Statistic to Use? Universitas Psychologica, 14, 15-24. https://doi.org/10.11144/Javeriana.upsy14-1.pbad

[26] Lavalle-González, F.J., Villarreal-Pérez, J.Z., González-González, G., MontesVillarreal, J., et al. (2011) Validation of the Measurement of Cortisol in Saliva of a Population of Young Adults. Revista de Endocrinología y Nutrición, 19, 146-148.

[27] The Measurement of Well-Being through Subjective Indicators: A Review. Pablo Villatoro S. Naciones Unidas. CEPAL 2012.

[28] Terrones-González, A., Salvador-Moysén, J., Lechuga-Quiñones, A.M., MartínezLópez, Y., et al. (2003) Differences in State-Trait Anxiety between Adolescents with Pregnancy-Induced Hypertension and Healthy Pregnancy Adolescents. Ansiedad $y$ Estrés, 9, 7-16.

[29] Minguet, R.R., Cruz, P.R., Ruíz Rosas, R.A. and Hernández, V.M. (2014) Incidence of Preterm Births in the IMSS (2007-2012). Ginecologia y Obstetricia de Mexico, 82, 465-471. 
[30] López, G.B., Ávalos, A.N. and Díaz Gómez, N.B. (2018) Incidence of Premature Infants at the High Specialty Naval General Hospital 2015-2017. Revista de Sanidad Militar México, 72, 19-23.

[31] Pérez Molina, J.J., Cobián López, B.E. and Silva Maciel, C.A. (2004) Maternal Risk Factors and Premature Birth in a Public Hospital in Western Mexico. Ginecología $y$ Obstetricia de México, 72, 142-149.

[32] Franco, M.J., Tun, C.M.R., Hernández, G.J.R. and Serralta, P.L.E. (2018) Risk Factors for Low Birth Weight According to the Multiple Logistic Regression Model. Retrospective Cohort Study in the José María Morelos Municipality. Quintana Roo, México. Medwave, 18, e7143. https://doi.org/10.5867/medwave.2018.01.7143

[33] Rodríguez, G.L.M., Romero, T.P., Andrade, G.M., Velázquez, L.M. and Rodríguez, G.R. (2005) Low Birth Weight Prevalence and Associated Factors. Ginecología $y$ Obstetricia de México, 73, 132-136.

[34] (2017) Metas mundiales de nutrición 2025 Documento normativo sobre bajo peso al nacer. Ginebra WHO/NMH/NHD/14.5.

[35] Blas, E., Gilson, L., Kelly, M.P., Labonté, R., Lapitan, J., Muntaner, C., et al. (2008) Addressing Social Determinants of Health Inequities: What Can the State and Civil Society Do? The Lancet, 372, 1684-1689. https://doi.org/10.1016/S0140-6736(08)61693-1

[36] WHO (2014) A Policy Guide for Implementing Essential Interventions for Reproductive, Maternal, Newborn and Child Health (RMNCH). A Multisectoral Policy Compendium for RMNCH. 